\title{
In Theory: Garbage In, Garbage Out
}

As soon as I had finished my doctor's thesis, I started working on wave problems, because now there was really no particular hurry about the whole thing. I could take my own time and, if I didn't get anywhere in two years, I could wait for the third year. We had in Leipzig at that time also a visit from some of the Norwegians. In fact, they came over to Leipzig quite often, and at that time V. Bjerknes and Solberg came. The first time I met V. Bjerknes was in our library at Leipzig. He was sitting there and he called me over, and I was very much interested in what this great man would say - the head honcho or the pope of polar front theory.
And he asked me: Is there a wastepaper basket in the library? I said: "Jawohl, Herr Professor" (I said it in German), and I showed him where it was. Then he explained to me-and I've never forgotten that good advice- that the wastepaper basket and the eraser are the two main tools of a theoretical physicist.

-Bernhard Haurwitz, speaking at NCAR, 2 February 1983, and published as "Meteorology in the 20th Century: A participant's view," March 1985 BAMS.

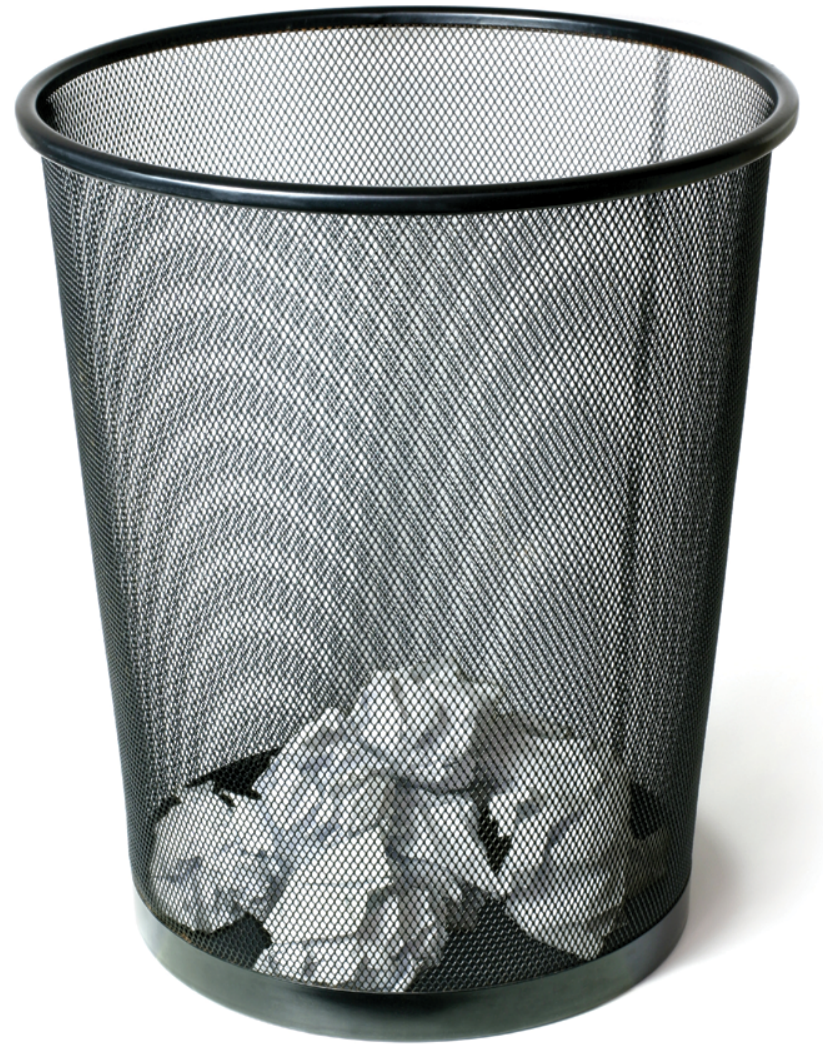

To read this article in the BAMS archives, see https://doi.org/I 0.1 I75/I520-0477(I 985)066<0282:MITCAP>2.0.CO;2 


\section{Find out from the authoritative source}

[ What's a dust devil? ]

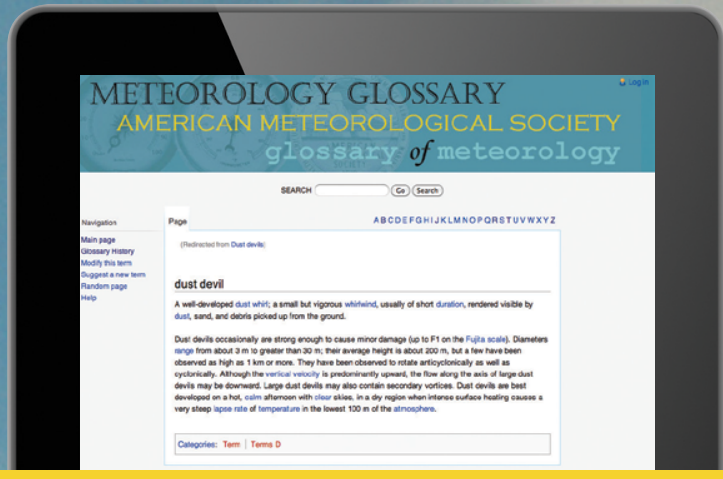

THE AMERICAN METEOROLOOICAL SOCIETV

\section{Online Glossary of Meteorology}

With over 12,000 meteorological terms, you'll be able to look up definitions online any time, any place, anywhere. http://glossary.ametsoc.org/wiki

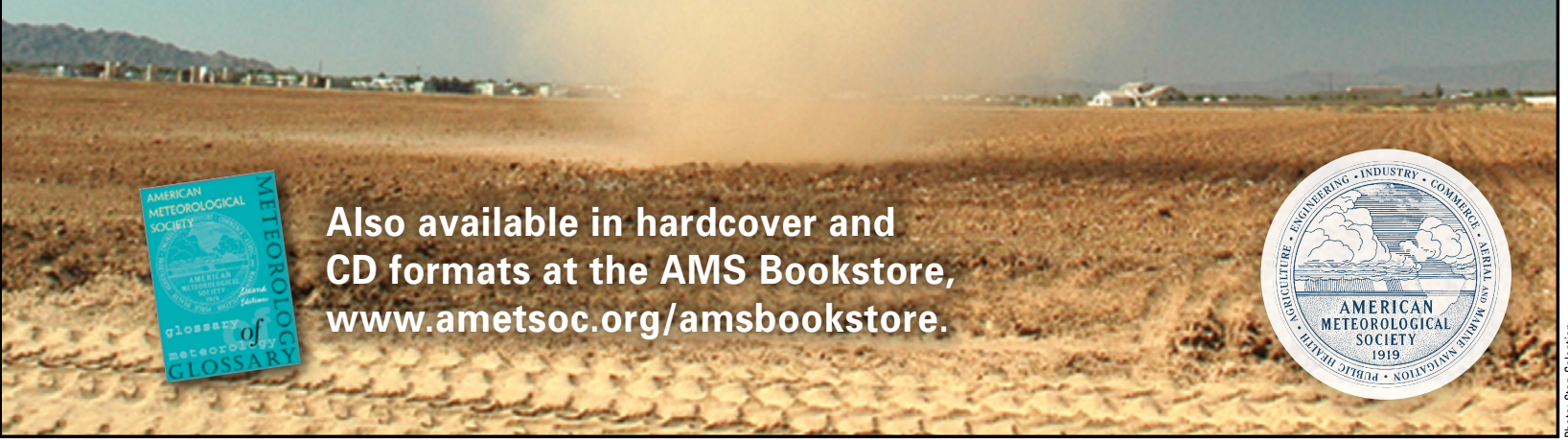

